lar to examine for the os uteri, as usual, in what I supposed to be similar cases, I carried my hand forward into the vagina, restoring the prolapsus. I subsequently placed her in bed with her hips raised, and left her for the remainder of the night, with the injunction that she should have an opiate to allay irritation and procure sleep if necessary.

The next morning I found her feverish, restless, and in pain in the recto-vaginal region, and on examination per vaginam the os uteri was found in its natural position, when a mystery began to hover around the case. Subsequently a consultation was solicited and obtained, but the cloud was not dispersed till several days after, when I was informed by her attendant that she had had a fæcal discharge from the vagina, accompanied with a "fleshy substance," which had been preserved for my inspection. On examination, it proved truly to be a fleshy substance, measuring, when fully extended upon the table, five inches by three, exhibiting its rectal and vaginal surfaces. The patient was again examined by passing the index finger of one hand into the anus and the same finger of the other hand jnto the vagina, when it was discovered that the recto-vaginal wall was gone, the fingers freely meeting and passing together along the two (?) canals. The sphincters, however, remained entire. The course of treatment was simple, but successful. The bowels were kept freely open with laxatives and demulcents, accompanied with antiseptic injections with laudanum. Fæcal discharges passed wholly from the vagina for about three weeks, when it was announced that she had had a discharge per via naturalis; from which time she rapidly improved, and before the close of March I again dismissed my patient, doing well. Since then she has borne three children. Her labors have not been unusually severe. The cicatrix is sound and perceptible to the touch, inclining a little to the left of the centre.

Queries.-Did the disease commence in the rectum in the early part of the first confinement? and if so, was there an actual inflammation pervading the rectum which induced costiveness? or was it nothing more than a loss of tone of the muscular fibres? and would my patient probably have got well without the loss of the "partition wall," had she followed my advice instead of indulging with patent drastics? What was the projection from the vagina, while vomiting, but the recto-vaginal wall, being favored by hardened fæces in the rectum? Yours truly,

West Amesbury, Jan. 18th, 1841. Benj. Atminson.

\title{
SUCCESSFUL OPERATION FOR STRABISMUS AND ECTROPEON.
}

BY P. W. ELLSWORTH, M.D., HARTFORD, CONN.

[Communicated for the Boston Medical end Surgical Journal.]

ThE operation for the cure of strabismus was performed by myself, January 9 th, upon Mr. C. S., of this city, 23 years of age. The deformity originated in a burn when the patient was about five months old. Not only strabismus inwards of the left eye was produced, but very great ectropeon, owing to contraction of the cicatrices, greatly distorting the face. For this last deformity Mr. S. was operated on by myself 
several months since. The elongation of the eye-lids downwards and outwards, and the eversion of the lower one, were so great, that it was found necessary to unite their elgres towards the outer canthus. This was done by paring their edgres three-eigluths of an incl, and taking a single suture. The object intended was accomplished, and the appearance of the eye much improved. Mr. S. now desired to be relieved of the strabisınus; which was accomplished in the following manner, very much as recommended by Liston.

The globe of the eye was fixed with a fine double hook, the superior lid elevated by a narrow speculum constructed for this purpose, and held by an assistant, and the lower lid depressed by the Gunger of another. A fold of conjunctiva was then raised with forceps having minute teeth, divided with curved scissors, the muscle exposed by a little dissection of the submucous cellular tissue, a blunt hook passed under, and the tendon divided by another cut with the scissors.

Fixing the eyeball is sometimes dispensed with. I have operated both with and without, and some others do the same, but it appears to me that unless the patient has much fortitude, the double hook should be used. If not, the rolling of the eye removes the muscle from the line of search and prolongs the operation. Probe-pointed scissors, cutting nicely to the point, easily expose the sclerotic coat, and do not endanger the eye, even if the patient is restless, nor alarm as much as the idea of a knife. For myself I much prefer the forceps for raising the conjunctiva ; it takes readier loold than a hook, and if any dissection is necessary, is more convenient. For if the tendon is not immediately found, the cellular tissue becomes filled with blood, and is not easily managed with the latter instrument. Minute teeth, amounting to little more than a mere roughness of the point, render the hold upon the slippery membrane more certain, and add nothing to the pain. Mr. S., during the whole operation, complained of nothing except pressure upon the ball with the speculum, and was surprised when informed that the operation was completed.

The time occupied in the division of the muscle in this case, from the first clip through the conjunctiva, might have occupied a minute or a minute and a half, though no exact reckoning was kept of time; nothing happened to cause any delay in its completion. For a few days the eye had a slight inclination outwards from the action of the antagonist muscle; this has ceased, and it is now perfectly straight. The power of rotating the eye inward is daily increasing, but like the other eye it is obedient only to the will.

So far as an operation can be successful, this is complete. It remains to be seen whether improvement in vision will follow to the extent stated by writers on this subject. In the case of Mr. S., the eye operated on is somewhat weaker than its fellow, though I believe it to be mainly owing to disease; if so, he may hope for the best. The application of cold water was all that was necessary, to keep down inflammation or allay pain. A fungous growth required the application of nitrate of silver, and is now almost entirely gone.

The only cases I have operated on were cured by division of the in- 
ternal rectus. I shall in a few days operate in a case where the external rectus is at fault, the patient being obliged to delay a short time.

January 20, 1840.

\section{DISEASE OF THE LUNGS, WITH TEMPORARY LOSS OF VOICE.}

\section{To the Editor of the Boston Medical and Surgical Journal.}

SıR,-The following case of disease of the lungs, with loss of voice, may have some interest with some of your readers.

The subject is a married lady, about 35 , the mother of two children. She is a slender woman, and has been subject to cough in the winter for some years. She has also been subject to dyspepsia, which has been removed by a visit to the Springs and a free use of Congress water. In the month of February, 1840, her cough was worse than usual. It increased daily till it became very severe, accompanied with pains in the chest and loss of voice. Such had been her situation a week or two when I visited her. She complained now of cough, pains in the chest, and a sense of great weight on the shoulders. She could not sleep well at night, and when she did she awoke faint, requiring more?air. There was soreness of the throat and fauces. Her countenance was sallow, with very great pallor of the lips. The pulse was small, about 100 . The respiration was hurried, and produced a cough at a full inspiration. The cough was hard and frequent; the expectoration small, and some streaked with blood. She could not lie on either side. On percussion there was flatness at the upper part of both sides, but greatest on the left. On auscultation at these parts, on the right side the vesicular respiration was heard, louder than natural. On the left side it could not be heard. The menstrual function was regular, but at these times there was faintness for many days. I directed the use of antimonials as largely as could be borne. To procure sleep, the extract of conium from 1 to 3 grains; which answered well. In a few days counter-irritation was used, and kept up by the tartar ointment. Under these remedies there was some amendment of the cough and pains in the chest ; the expectoration became quite copious, and not often streaked with blood.

She continued thus, with some cough, particularly in the morning; with inability to lie on the left side (for she was now able to lie on the right), and pains through the collar bones. The soreness of the throat had yielded to a gargle of the nitrate of silver; but there was no restoration of voice. Such was the state of her health for many months. As soon as the weather would permit, she rode out daily, and soon walked out in the middle of the day. I directed her to use the elixir vitriol three times a day in doses of a teaspoonful, ?which was the only tonic that she could bear. The weather having now become warm, I advised her to use the warm salt-water baths every other day, which she continued for six weeks, gaining strength under the use of them. In July I persuaded her to go into the country. She there tried electricity to the region of the throat, but it rather increased the pains in the chest, 